\title{
Percepção dos profissionais de saúde na pandemia por COVID-19: desafios e estratégias para prática profissional
}

\author{
Perception of health professionals in the COVID-19 pandemic: challenges and strategies for \\ professional practice \\ Percepción de los profesionales de la salud en la pandemia COVID-19: retos y estrategias para la \\ práctica profesional
}

Recebido: 26/07/2021 | Revisado: 05/08/2021 | Aceito: 08/08/2021 | Publicado: 13/08/2021

\author{
Ana Cristina da Silva Oliveira \\ ORCID: https://orcid.org/0000-0002-8414-2561 \\ Centro Universitário Anhanguera de Niterói, Brasil \\ E-mail: ana.coliveira@educadores.net.br \\ Giuliana Fernandes e Silva \\ ORCID: https://orcid.org/0000-0002-1130-2587 \\ Centro Universitário Anhanguera de Niterói, Brasil \\ E-mail: giulianafernandes@hotmail.com \\ Luiz Carlos Moraes França \\ ORCID: https://orcid.org/0000-0002-6370-115X \\ Centro Universitário Anhanguera de Niterói, Brasil \\ E-mail: luiz.franca@educadores.net.br \\ Gleiciana Sant' Anna Vargas \\ ORCID: https://orcid.org/0000-0002-9523-7304 \\ Centro Universitário Anhanguera de Niterói, Brasil \\ E-mail: gleiciana.vargas@educadores.net.br \\ Gabrielle Firmino \\ ORCID: https://orcid.org/0000-0003-2083-681X \\ Centro Universitário Anhanguera de Niterói, Brasil \\ E-mail: gabriellefirmino98@gmail.com
}

\begin{abstract}
Resumo
Objetivo: Descrever a percepção dos profissionais de saúde sobre a assistência no contexto da pandemia por Covid-19 e propor estratégias preventivas frente aos riscos de contaminação no âmbito hospitalar. Método: Pesquisa qualitativa, descritiva e exploratória. Para coleta de dados utilizou-se entrevista semiestruturada, e para organização e análise do material, análise de conteúdo de Bardin. O estudo foi realizado com a participação de profissionais de saúde de um hospital na região metropolitana do Rio de Janeiro/Brasil. A pesquisa foi aprovada pelo Comitê de Ética em Pesquisa. Resultados: Os profissionais descreveram o medo frente ao risco de contrair a doença e serem veículo de transmissão à outras pessoas. A alta taxa de mortalidade impactou a percepção sobre o novo Corona vírus e a percepção do profissional nos cuidados diários com os pacientes. Alguns profissionais descreveram sobre a preocupação na vivência em outras instituições e apontaram o receio em relação a falta de equipamentos de proteção individual, o cansaço do trabalho e a necessidade de seguir os protocolos de biossegurança além da comunicação entres os profissionais. Os profissionais consideram importante a presença de protocolos nas unidades de saúde que recebem pacientes acometidos pela COVID-19 e, afirmam consultar esses documentos para recordarem das estratégias e recomendações. Conclusão: Diante da complexidade do trabalho em cenário hospitalar, compreender aspectos gerais de administração e da organização do trabalho em saúde, é necessário, para ampliar competências, habilidades e atitudes para desenvolver uma prática segura.
\end{abstract}

Palavras-chave: Contaminação biológica; Pandemias; Equipamento de proteção individual; Protocolos; COVID-19.

\begin{abstract}
Objective: To describe the perception of health professionals about care in the context of the Covid-19 pandemic and to propose preventive strategies against the risks of contamination in the hospital environment. Method: Qualitative, descriptive and exploratory research. For data collection, semi-structured interviews were used, and Bardin's content analysis was used to organize and analyze the material. The study was carried out with the participation of health professionals from a hospital in the metropolitan region of Rio de Janeiro/Brazil. The research was approved by the Research Ethics Committee. Results: Professionals described their fear of the risk of contracting the disease and being a vehicle for transmission to other people. The high mortality rate impacted the perception of the new Corona virus and the professional's perception in the daily care of patients. Some professionals described the concern in living in
\end{abstract}


other institutions and pointed out the fear regarding the lack of personal protective equipment, fatigue from work and the need to follow biosafety protocols in addition to communication between professionals. Professionals consider the presence of protocols in health units that receive patients affected by COVID-19 to be important and claim to consult these documents to remember the strategies and recommendations. Conclusion: Given the complexity of work in a hospital setting, understanding general aspects of administration and organization of work in health is necessary to expand skills, abilities and attitudes to develop a safe practice.

Keywords: Biological contamination; Pandemics; Personal protective equipment; Protocols; COVID-19.

\begin{abstract}
Resumen
Objetivo: Describir la percepción de los profesionales de la salud sobre la atención en el contexto de la pandemia Covid-19 y proponer estrategias preventivas frente a los riesgos de contaminación en el entorno hospitalario. Método: Investigación cualitativa, descriptiva y exploratoria. Para la recolección de datos se utilizaron entrevistas semiestructuradas y el análisis de contenido de Bardin para organizar y analizar el material. El estudio se llevó a cabo con la participación de profesionales de la salud de un hospital de la región metropolitana de Río de Janeiro / Brasil. La investigación fue aprobada por el Comité de Ética en Investigación. Resultados: los profesionales describieron su temor al riesgo de contraer la enfermedad y ser un vehículo de transmisión a otras personas. La alta tasa de mortalidad impactó la percepción del nuevo virus Corona y la percepción del profesional en el cuidado diario de los pacientes. Algunos profesionales describieron la preocupación de vivir en otras instituciones y señalaron el temor por la falta de equipo de protección personal, el cansancio del trabajo y la necesidad de seguir protocolos de bioseguridad además de la comunicación entre profesionales. Los profesionales consideran importante la presencia de protocolos en las unidades de salud que reciben pacientes afectados por COVID-19 y afirman consultar estos documentos para recordar las estrategias y recomendaciones. Conclusión: Dada la complejidad del trabajo en el ámbito hospitalario, es necesario comprender los aspectos generales de la administración y organización del trabajo en salud para ampliar las habilidades, habilidades y actitudes para desarrollar una práctica segura.
\end{abstract}

Palabras clave: Contaminación biológica; Pandemias; Equipo de protección personal; Protocolos; COVID-19.

\title{
1. Introdução
}

Os trabalhadores da área da saúde estão expostos a inúmeros riscos ocupacionais causados por agentes físicos, químicos, biológicos, ergonômicos e psicossociais, os quais podem causar lesão corporal, perturbação funcional, redução da capacidade laboral ou problemas de ordem psicológica. Dentre estes, em função da sua rotina de trabalho, os profissionais de enfermagem apresentam uma maior exposição ao risco biológico (Oliveira, Macedo, Morais, Tanan \& Yarid, 2017). O cotidiano destes profissionais pode expor uma realidade difícil, repleta de obstáculos que compõem um cenário com situações adversas envolvendo a relação profissional-paciente. O risco de contaminação, no contexto atual, se tornou uma das objeções enfrentadas diante de uma rotina árdua em prol da saúde.

Ao considerar situações vivenciadas com doenças contagiosas, como por exemplo a varíola, febre amarela e sarampo, sabe-se que a contaminação dos profissionais ocasiona preocupação social, visto que esses trabalhadores lidam diretamente com os pacientes infectados, aumentando assim o risco de contaminação entre a equipe. Em 11 de março de 2020 a Organização Mundial de Saúde (OMS) caracterizou como estado de pandemia o surto mundial da doença causada pelo corona vírus SARS-CoV-2 (coronavirus 2) denominada como COVID-19 (coronavírus SARS-CoV-2), o que levou os serviços de saúde a um novo cenário de ações em saúde e segurança voltada aos diversos profissionais envolvidos nos cuidados à população (Gallasch, Cunha, Pereira \& Silva-Junior, 2020; Organização Panamericana de Saúde, 2020).

Os profissionais que estão na linha de frente precisaram se adaptar diante do elevado grau de contágio do novo corona vírus, o que demandou atenção redobrada e esforço físico e mental.

Os profissionais da enfermagem têm enfrentado rotineiramente precarização no processo de trabalho e inúmeros problemas no sistema de saúde, como falta de infraestrutura para o atendimento, escassez de insumos, dimensionamento inadequado de pessoal, falta de Equipamentos de Proteção Individual (EPI), jornadas extensas, sobrecarga de trabalho, baixos salários e falta de capacitação, entre outros (Quadros, Fernandes, Araujo \& Caregnato, 2020).

No Brasil, adotou-se a medida de isolamento social para evitar a propagação rápida do vírus, bem como a quarentena de pacientes com a doença. Enquanto isso, profissionais da saúde enfrentam muitas dificuldades para lidar com a pandemia 
como a falta de equipamentos de EPI, equipamentos inadequados ou insuficientes, além de falta de leitos, medicamentos e ventiladores mecânicos invasivos. Diante disto, vê-se profissionais da saúde, em especial a equipe de enfermagem, doentes ou faleceram em decorrência da COVID-19 (Jackson et al., 2020).

Esses problemas no sistema de saúde já existiam, porém foram agravados devido à pandemia. Nesse contexto, fica ainda mais evidente o esforço coletivo dos profissionais de saúde para controlar o atual cenário (Quadros, Fernandes, Araujo \& Caregnato, 2020).

Entretanto, o medo tem se tornado uma constante na vida desses trabalhadores, que além de lidar com o risco de contaminação, os profissionais passaram a encarar problemas divergentes que transcendem à contaminação. Entres estes, o receio em trabalhar com o risco de algo novo, medo de contágio e transmissão para suas próprias famílias ou até mesmo de contaminar outros pacientes internados com outras patologias (Teixeira et al., 2020).

$\mathrm{Na}$ cadeia de ações para proteger os trabalhadores, a barreira ao contato de risco prolongado com pacientes infectados é um método fundamental de segurança no trabalho. No que tange a COVID-19, a eficácia do EPI está relacionada ao fornecimento de equipamentos com a proteção suficiente para o SARS-CoV-2 e o treinamento adequado das equipes de trabalhadores para o uso correto e consistente (Gallasch, Cunha, Pereira \& Silva-Junior, 2020). A necessidade de manter a equipe sempre atualizada, contribui para mantê-los sem inseguranças e confortáveis para realizar os procedimentos necessários. Os protocolos oferecidos pela unidade permitem uma relevante organização na assistência e comunicação ativa entre a equipe multiprofissional (Arantes, Rocha, Pereira \& Nascimento, 2021).

Frente a este cenário de preocupação e incertezas, questiona-se: qual a percepção dos profissionais de saúde no contexto de pandemia por covid-19? Considerando o cenário atual e a necessidade de fundamentar ações que contribuam na rotina profissional dos trabalhadores da saúde, este estudo teve como objetivo: Descrever a percepção dos profissionais de saúde sobre a assistência no contexto da pandemia por Covid-19 e propor estratégias preventivas frente aos riscos de contaminação no âmbito hospitalar.

\section{Metodologia}

Trata-se de um estudo do tipo qualitativo, descritivo e exploratório. A análise qualitativa é uma atividade intensa que exige criatividade, sensibilidade conceitual e trabalho árduo. A finalidade da análise de dados é organizar, fornecer estrutura e extrair significado das informações da pesquisa, além de oferecer uma melhor compreensão dos valores culturais e das representações de um determinado grupo sobre temas específicos, por meio de trabalho com um universo de crenças, motivos, significados, valores e atitudes, correspondendo a um espaço mais profundo das relações dos processos e dos fenômenos, que não podem ser reduzidos à operacionalização de variáveis (Minayo, 2014).

A análise foi realizada no contexto da pandemia pelo Covid-19, conferindo o caráter exploratório da pesquisa. O estudo foi desenvolvido em um hospital na região metropolitana do estado do Rio de Janeiro, através de análises de entrevistas de profissionais da saúde.

O período para coleta de dados ocorreu entre os meses de janeiro a abril de 2021. A coleta de dados ocorreu por meio de entrevista individual no próprio cenário, em sala reservada e mantendo o distanciamento entre o entrevistador e o entrevistado. A amostra do estudo foi composta por 27 profissionais da saúde (Enfermeiros, técnicos de enfermagem e fisioterapeutas). Como critério de inclusão foram selecionados profissionais que aceitaram participar do estudo através do preenchimento do Termo de Consentimento Livre e Esclarecido (TCLE) e estivessem disponíveis no momento da entrevista. Foram excluídos profissionais ausentes no momento da pesquisa por falta ou não disponíveis por licença, gravidez, motivos de saúde e outros. Para coleta de dados foi realizado entrevista utilizando-se um instrumento semiestruturado, elaborado pelos autores, focando aspectos relacionados ao trabalho, ao conhecimento e adesão ao uso de EPI e aos riscos de exposição. Após a 
coleta das informações, as entrevistas foram transcritas e seguiu-se com análise de conteúdo temático (Minayo, 2014), com leitura minuciosa do material empírico, buscando as ideias principais, a exploração do conteúdo, constituindo-se as categorias temáticas dos fragmentos dos depoimentos; posteriormente, realizou-se o confronto das categorias que emergiram analisadas e sustentadas nos referenciais. A análise dos dados foi feita de forma manuscrita. A análise de conteúdo é definida como um método empírico. Trata-se de um conjunto de instrumentos de cunho metodológico em constante aperfeiçoamento, que se aplicam a discursos (conteúdos e continentes) diversificados.

Os critérios de organização da análise são divididos em pré-análise, exploração do material ou codificação e tratamento dos resultados (Bardin, 2011). Na fase inicial de pré-análise, o material é organizado, compondo o corpus da pesquisa. Segundo Bardin (2011), escolhem-se os documentos, formulam-se pressupostos e elaboram-se indicadores que norteiam a interpretação, porém é fundamental seguir as regras de exaustividade, representatividade, homogeneidade, pertinência e exclusividade. A leitura flutuante ocorre por meio do contato inicial com os documentos, quando se procura responder à questões norteadora do estudo, direcionando às afirmações iniciais que podem ser comprovadas ou refutadas ao final (Bardin, 2011).

No momento posterior de exploração do material, os dados são codificados, processo em que passam por uma transformação sistemática e são agregados em Unidades de Registro (URs) (Bardin, 2011). A elaboração e construção das categorizações surgiram da releitura das transcrições das entrevistas para identificação das unidades de significado, na forma de temas para análise. Por meio da leitura de cada entrevista, foi estabelecida a classificação por temas para a construção das unidades de significação.

Na terceira etapa, o tratamento dos resultados corresponde à inferência e à interpretação, caracterizados pela fase da reflexão e intuição, com embasamento dos materiais empíricos. As unidades de significação, correspondentes aos temas ou categorias de análise de dados, foram elaboradas pela associação de um conjunto de URs em quantidade e qualidade representativa das informações que viabilizasse uma análise consistente dos dados disponibilizados em cada uma das entrevistas (Bardin, 2011).

O sigilo da identificação dos entrevistados foi preservado, utilizando a estratégia de representação alfanumérica nos depoimentos transcritos conforme a ordem que ocorreram as entrevistas (E1, E2, E3....). Após convite e conhecimento sobre o estudo os participantes aceitaram participar voluntariamente da pesquisa. Como critério de inclusão, os profissionais deviam estar em exercício ativo de sua função e concordar em participar do estudo mediante a assinatura do Termo de Consentimento Livre e Esclarecido.

A pesquisa foi aprovação pelo Comitê de Ética em Pesquisa da UNIAN de São Paulo - CEP/UNIAN, sob CAAE N ${ }^{\circ}$ 35663920.7.0000.5493, atendendo a Resolução 466/2012 de pesquisas que envolvem seres humanos e atendeu a Resolução 510/2016 do Conselho Nacional de Saúde a qual determina diretrizes éticas específicas para as ciências humanas e sociais.

\section{Resultados e Discussão}

A pandemia de Covid-19 tem produzido números expressivos de infectados e de óbitos no mundo. Nesse universo, os profissionais de saúde constituem um grupo de risco por estarem expostos diretamente aos pacientes infectados, o que faz com que recebam uma alta carga viral. Além disso, estão submetidos a enorme estresse ao atender esses pacientes, muitos em situação grave, em condições de trabalho, frequentemente, inadequadas (Teixeira et al., 2020).

$\mathrm{Na}$ análise das entrevistas observou-se um quantitativo maior e mais significativo de URs dentro de alguns assuntos e temas, e foi justamente o que definiu as unidades de significação, e que foram definidas como as categorias emergentes de análise dos dados. No universo dos resultados encontrados os participantes descreveram e expressaram algumas dificuldades na rotina de trabalho no atual contexto da pandemia, os medos e angústias, a necessidade de uma abordagem em treinamentos 
e outras estratégias que podem ser efetivas frente ao cenário que vivenciam. Por meio da leitura e releitura, análise minuciosa e embasada no referencial elencado emergiram duas categorias: O desafio dos profissionais no enfrentamento da pandemia pelo COVID-19 e, Protocolos assistenciais e treinamentos: estratégias para prática assistencial.

\section{Categoria 1: O desafio dos profissionais no enfrentamento da pandemia pelo COVID-19}

Diante das entrevistas realizadas, o medo, preocupação e ansiedade foram elementos destacados na fala dos participantes e que trouxeram impacto na rotina de trabalho da assistência a saúde. Todos os profissionais descreveram o medo frente ao risco de contrair a doença e serem veículo de transmissão à outras pessoas. Por serem profissionais atuando diretamente na "linha de frente" no enfrentamento da pandemia, essa preocupação tornou-se realidade para muitos trabalhadores em todos os países (Bezerra et al., 2020)

Há evidências que indicam o alto grau de exposição e contaminação dos profissionais de saúde pelo COVID-19. Estudo realizado em um Hospital de referência com 3.300 leitos, com uma coorte retrospectiva com profissionais de saúde, especialmente médicos clínicos e enfermeiros, evidenciou a existência de 72 profissionais que atuaram na linha de frente infectados com COVID-19, identificando-se associação entre o aumento da jornada de trabalho, com a inadequada higienização das mãos e o risco de contrair a infecção (Ran et al., 2019). Se for manter o termo "muitas" para descrever as evidências, citar as diversas fontes que contextualizaram essa afirmação.

A apreensão sobre o risco é real e teve representações similares entre os entrevistados como pode ser observado a seguir.

\footnotetext{
"Tive medo, não só por mim, mas pelo próprio paciente. Porque a pandemia foi divulgada e logo tiveram muitas mortes. Então a gente olha o lado mais pessoal, o medo de se contaminar, de contaminar colegas, de contaminar quem está em casa, é um grande receio." (E5)

"Uma dificuldade eu tive na parte psicológica. Eu acho que foi o pior pra mim. Porque foi uma coisa nova que surgiu e a gente teve medo. Ficamos preocupados por que tinha muita gente morrendo, então isso psicologicamente afetou a todos." (E3)

"No início era algo novo e a gente ficava com medo de se contaminar. Por mais que você se proteja, que aprenda a fazer com o treinamento [...] a gente ficava com medo contaminar o que está usando [EPI] e se contaminar. Porque é algo novo e ninguém conhecia. Hoje em dia, parece que é mais fácil todo esse preparo." (E12)
}

O medo pelo desconhecido foi prevalente na percepção dos entrevistados. A maioria dos profissionais destacou o receio pelo contágio da doença e a preocupação em transmissão para outros pacientes, familiares e amigos. A alta taxa de mortalidade impactou diretamente a percepção sobre o novo Corona vírus e a percepção do profissional nos cuidados diários com os pacientes. Nesse sentido, muitos profissionais descreveram sobre os danos psicológicos e emocionais que enfrentaram na pandemia e o quanto isso repercutiu na sua rotina de trabalho. De acordo com Paula et al. (2020) o medo da morte, e de infectar com o vírus, é um sentimento que tem acompanhado pessoas por todo mundo, sobretudo os profissionais de enfermagem que estão na linha de frente.

Estudo realizado na China concluiu que médicos e enfermeiros em hospitais que assistem pacientes com COVID -19 apresentam sintomas de depressão, ansiedade, insônia e angústia, e ressaltam as intervenções especiais para promover o bemestar mental desses profissionais com uma atenção mais cuidadosa aos que estão na linha de frente (Oliveira et al., 2020). 
Além do medo, os entrevistados relataram um grave problema relacionado a falta de insumos para realizarem os atendimentos necessários na prática assistencial. Descreveram, também, sobre a preocupação frente a falta de vagas direcionadas à assistência nos casos de COVID-19.

"Tem sempre uma preocupação com as vagas e leitos para os pacientes. As vezes não tem vaga para o CTI Covid, não tem vaga para o andar, não tem vaga para nenhum setor. Então quando recebemos um paciente suspeito de Covid na emergência, é preocupante ficar com ele ocupando um leito na emergência sem saber como vai ser o próximo paciente que chega, que pode ser um trauma, um infarto, um AVC... isso é o mais difícil. Porque antes a gente recebia o paciente na emergência, estabilizava e encaminhava para outro setor" (E18)

É evidente que a preocupação dos profissionais em relação à assistência tem se elevado nesse período pandêmico. A falta de Equipamentos de Proteção Individual é apenas o início de uma série de reivindicações apresentadas por colaboradores da área da saúde. Os profissionais entrevistados relataram que a sobrecarga na rotina de trabalho e a falta de materiais necessários podem ser capazes de desencadear problemas na vivência dos trabalhadores no ambiente hospitalar, como o estresse excessivo, ansiedade e insegurança no atendimento.

De acordo com Dantas, 2021, os profissionais além de apresentarem maior risco de infecção pelo novo vírus, estão expostos à possibilidade de que faltem equipamentos de proteção individual, ventiladores mecânicos, insumos hospitalares, além de precisarem decidir, por vezes, quais pacientes terão direito a determinadas tecnologias assistivas.

Alguns profissionais descreveram ainda uma preocupação na vivência em outras instituições e apontaram o receio em relação a falta EPI, o cansaço do trabalho e a necessidade de seguir os protocolos de biossegurança além da comunicação entres os profissionais.

“Na minha prática em outros hospitais eu tenho uma preocupação com a falta de equipamentos pra proteção." (E26)

"Aqui a gente não tem muita dificuldade, porque aqui a gente tem todo o aparato, a dificuldade é menor. Mas na outra instituição que eu trabalho, as vezes falta material, falta EPI, dificuldade na comunicação entre a equipe [...], são problemas que dificultam o enfrentamento de uma doença como essa. " (E17)

Segundo Dantas (2021), Dantas foi citado no parágrafo anterior. Citar outro autor ou autores junto a este para trazer maior impacto visto que há muitas publicações sobre esse tema em discussão. neste momento de crise, os gestores de instituições de saúde, alinhados com os níveis governamentais, devem pensar atitudes que ao menos minimizem o desgaste psicossocial dos profissionais de saúde. Podem-se organizar plantões de atendimento psicológico nas instituições hospitalares, disponibilização de material on-line sobre redução de ansiedade, medo e desespero em momentos de crise, treinamentos constantes para intensificar a segurança na prestação da assistência, contratação emergencial de mais profissionais para diminuição de sobrecarga laboral e garantia de EPI.

De fato, a falta de equipamentos de proteção individual foi uma notícia divulgada em outros cenários e países, em que o rápido aumento por sua demanda levou a um acréscimo sobre o risco de infecção por profissionais de saúde devido à sua falta em número suficiente (Goés et al., 2020).

Cabe ressaltar que existe um debate no âmbito dos organismos internacionais com relação ao uso de EPIs pelos profissionais de saúde. A OMS recomenda o uso de máscaras cirúrgicas para os profissionais responsáveis por procedimentos de rotina e de máscara N95 para o cuidado de pacientes com procedimentos que geram aerossóis. Nesse sentido, de acordo 
com o procedimento assistencial, o EPI deve ser ofertado ao profissional garantindo a segurança necessária para o atendimento (Rodrigues \& Silva, 2020).

Por ser um vírus novo, os profissionais evidenciaram estar inseguros, também, em relação a credibilidade de outros colegas e pacientes diante do novo corona vírus. Essa representação pode ser verificada nas expressões a seguir:

"Eu acho que primeiramente o importante é a gente aceitar a doença. Ainda tem muita gente descrente. Porque logo no início tudo era suspeito, mas depois confirmou-se que a doença existe e está contaminando muita gente. Perdi amigos do trabalho, vizinhos, parentes [...]. Mas ainda tem uma dificuldade em fazer com que o outro entenda que ela [doença] realmente exista." (E6)

"A resistência dos pacientes em acreditar na doença é ruim e é difícil conseguir conscientizar que ela existe. Eles não dão muita atenção, acham que é bobagem." (E9)

"Eu acho que a maior dificuldade é tanto o paciente quanto acompanhante cair em si, que as vezes um descuido em ir pra uma festa, ou um lugar que tá proibido, pode ser fatal." (E14)

A desinformação relacionada à ciência tem sido uma das grandes preocupações atuais e os desafios para enfrentá-la tem se intensificado neste momento em que o mundo atravessa uma pandemia. A OMS anunciou que estávamos atravessando não apenas uma pandemia, mas também uma infodemia. Este termo é definido como a "ciência da distribuição e dos determinantes da informação em meio eletrônico, especificamente a Internet, ou na população, com o objetivo final de informar sobre saúde pública e política pública” (Haraki, 2021). Ainda segundo Haraki, 2021, a infodemia representa um sério problema para a saúde pública visto que os profissionais também se tornaram vítimas da mesma, pois pode ocorrer a geração de pânico na população, fazendo com que pessoas corram para comprar e estocar suprimentos e medicamentos que podem fazer falta onde realmente são necessários.

Essa preocupação com a desinformação na pandemia é enfrentada em outras realidades internacionais, como pôde ser acompanhado durante o ano de 2020 e 2021 informações falsas foram compartilhadas, inclusive em discursos de lideranças políticas, levando aos hospitais em vários países da Europa e na América a atenderem centenas de casos de intoxicação de substâncias que surgiram a partir de promessas de curas milagrosas nos ambientes digitais. Temas como fake news e pós-verdade têm proliferado no debate público, na agenda midiática e na própria academia. A literatura científica tende a associar a desinformação a um conjunto de elementos fixos para identificá-la a partir de tipologias (Oliveira, 2020). Nesse contexto, além dos esforções necessários para o enfrentamento da pandemia houve a necessidade de se trabalhar também uma árdua batalha na defesa da ciência e na correção das fake news. Um estudo de Oliveira (2020) descreve sobre três abordagens para o enfrentamento à desinformação que têm sido recorrentes na literatura científica, uma instrumental e classificatória sobre a verdade, através de ferramentas de checagem de fatos; uma normativa devedora das teorias democráticas deliberativas, que defende que os cidadãos possuem competências para tomar decisões racionais a partir de suas próprias buscas por informação; e a esperança na educação, a partir de ações de letramento midiático e informacional.

Nesse sentido, torna-se urgente discutir sobre as implicações das medidas que estão sendo disseminadas como soluções necessárias também para o enfrentamento da pandemia. Desta forma, a próxima categoria destaca estratégias destacadas pelos participantes que podem contribuir na rotina de trabalho dos profissionais da saúde na vivência hospitalar. 


\section{Categoria 2: Protocolos assistenciais e treinamentos: estratégias para prática assistencial}

Uma das estratégias empregadas na prática assistencial neste momento de pandemia é a utilização de protocolos escritos. Estes protocolos são disponibilizados para que a equipe tenha sempre acesso às informações e instruções para os atendimentos. Nas entrevistas realizadas, $70 \%$ dos profissionais consideraram importante a presença de protocolos nas unidades de saúde que recebam pacientes acometidos pela COVID-19 e, parte dos profissionais entrevistados afirmam consultar esses documentos para recordarem as estratégias e recomendações. A exemplificação sobre o destaque dos protocolos assistenciais em saúde pode ser visualizada nos fragmentos das entrevistas a seguir:

"Temos protocolos e isso é importantíssimo. Porque quando tá protocolado a gente tem um lugar pra pesquisar quando esquece, fica mais fácil e facilita muito o trabalho da gente.” (E2)

"Ter protocolo ajuda muito. Para não cair no esquecimento, e se você tem dúvida ou esquece, o documento está ali para poder acessar e fazer o correto." (E3)

“Ele [protocolo] é importantíssimo. Porque às vezes quando está protocolado você tem um lugar para pesquisar se acontecer de esquecer. Ou quando tem um funcionário novato, otimiza o tempo de buscar o passo a passo” (E27)

A organização de uma unidade de saúde é fundamental para que os atendimentos sejam eficientes e atendam a demanda de trabalho. No atual contexto pandêmico, os protocolos e treinamentos se tornaram uma rotina nos serviços. Ocorreram inúmeras mudanças na prática profissional, que se criaram na busca para evitar a proliferação do vírus e êxito na recuperação dos pacientes internados. Nessa perspectiva, para que os profissionais se atualizassem da nova realidade, foi necessário a aplicação de estratégias e instruções para nortear o processo de cuidado (Gerolin et al., 2020).

De acordo com Krauzer et al. (2018) fazem parte da organização do trabalho na área de saúde os protocolos assistenciais, constituindo como uma ferramenta importante no trabalho do gerenciamento, seja no cuidado ou organizacional. Estudo defende que o uso de protocolos pode ser um aliado importante para a melhoria da qualificação dos profissionais mediante a tomada de decisão assistencial, pois proporciona a disseminação de conhecimento, a comunicação profissional e a coordenação do cuidado, favorecendo assim, a uma assistência prestada de forma mais segura (Lima et al., 2020). Frente a análise dos depoimentos, a maioria dos participantes ressalta a relevância de tal estratégia que orientou e coordenou sua atuação, além da possibilidade de consulta contínua aos instrumentos disponibilizados na instituição.

A utilização dos protocolos para o cuidado em saúde é oportuno e auxilia na organização do trabalho (Arantes, Rocha, Pereira, \& Nascimento, 2021). Diante disto, a adoção dos protocolos assistenciais para o cuidado é conveniente e dá suporte e contribui para organização e gerenciamento dos profissionais de saúde (Krauzer et al., 2018).

É esperado que uma pandemia pressione os sistemas de saúde e estresse a capacidade de cuidados intensivos, de atuação segura da força de trabalho e da aquisição de suprimentos, principalmente, os essenciais para a proteção dos profissionais. Ter informações precisas e confiáveis é importante fator de apoio na decisão das estratégias de enfrentamento da pandemia. Dados epidemiológicos e estatísticos são essenciais para situar a capacidade de atendimento e prospectar mudanças organizacionais necessárias para atendimento de um novo contexto (Gerolin et al., 2020). Nesse sentido, a organização do trabalho depende de um estabelecimento sobre as normas, protocolos, regras e fluxos, e estes precisam ser compartilhados com os profissionais, de forma que as ações realizadas possam contribuir para o sucesso das atividades propostas no serviço de saúde.

Considerando a importância dos protocolos, os treinamentos oferecidos para melhor preparar os profissionais também 
é uma vertente relevante a ser observada. Entre as principais falas destacadas, observou-se ainda a necessidade da instituição de treinamentos às equipes sobre a abordagem dos protocolos e o resgate dos treinamentos que por vezes não fazem parte da rotina dos profissionais.

"Sim. Na época foi instituído protocolos. Considero importantíssimo. Eu acho que deveria haver mais treinamentos também." (E22)

"No início ficava todo mundo perdido. Faz assim, faz assado, usa isso, usa aquilo, teve muito medo e excesso de cuidado. Mas as vezes usa e não usa correto. Usa mas não sabe tirar, no caso dos EPIs. E a questão de cuidar do paciente mesmo, tipo, qual o primeiro cuidado, qual medicação para cada caso. Na época foi instituído protocolos. Considero importantíssimo. Eu acho que deveria haver mais treinamentos também, porque a gente esquece e as coisas mudam." (E27)

A educação continuada e educação permanente em saúde visam transformar a realidade a partir da modificação do comportamento via novos conhecimentos, levando-se em conta os processos educativos (Ribeiro et al., 2019). Desta forma, proporcionar esta prática como rotina nos serviços pode contribuir para mudanças positivas na rotina dos profissionais e evitar insegurança frente a novas abordagens na prática do cuidado em saúde.

A apresentação de novos protocolos, equipamentos e rotinas do serviço aproximam gestores dos profissionais e facilita a percepção de possíveis dificuldades e/ou erros que podem então ser corrigidos. Reduzir a ocorrência de eventos adversos pode ser considerado como um desafio a ser superado em relação à segurança do paciente. É sabido que a causa dos erros é multifatorial e principalmente quando os processos assistenciais são complexos e mal planejados, os profissionais e pacientes estão suscetíveis. Na assistência à saúde existe a possibilidade de riscos e danos ao paciente e esta realidade não pode ser ignorada (Milani \& Vandresen, 2019).

Frente ao exposto, os diferentes saberes provenientes de cada profissional, deflagra um cenário complexo em que compreender o saber de cada um, são condições determinantes para a reflexão crítica da realidade circundante (Freire, 1987). Face a esse pensamento em se tratando de um conhecimento que atrelado a prática, infere diretamente na assistência, tornandose necessário para melhor condicionante profissional.

Este estudo trouxe contribuições ao desvendar pela percepção de quem está atuando diretamente na assistência às vítimas acometidas pelo novo corona vírus, quais são os principais receios e dificuldades enfrentadas na rotina em um cenário hospitalar. Desta maneira, têm-se mais uma visão que pode ser utilizada para construção de possibilidades no enfrentamento deste desafio.

\section{Conclusão}

Considerando a necessidade de proteger os trabalhadores de saúde, é fundamental garantir o acesso ao EPI no combate à pandemia de Covid-19 e conscientizar sobre o uso racional destes equipamentos. Busca-se ainda, estratégias para diminuir os impactos desta crise, em especial sobre o adoecimento dos trabalhadores.

Frente a complexidade do trabalho em cenário hospitalar, compreender aspectos gerais de administração e da organização do trabalho em saúde, é necessário, para ampliar competências, habilidades e atitudes para desenvolver uma prática segura.

Faz-se necessário uma ação conjunta entre setores da saúde e os profissionais de saúde que possam garantir segurança, otimizando estratégias rápidas e seguras frente aos desafios da assistência e a garantia do uso adequado de EPI. A 
pesquisa destaca desafios que ainda precisam de atenção dos gestores da saúde e identifica lacunas que podem ser aprofundadas em novos estudos, no que diz respeito à descrição de novas ferramentas que possam ser utilizadas na atualização dos profissionais no processo trabalho.

\section{Referências}

Arantes, E. H., Rocha, D. R. da, Pereira, L. dos R., \& Nascimento, J. C. C. do. (2021). Protocolos assistenciais como ferramenta de trabalho no manejo clínico da covid-19 em unidade terapia intensiva: revisão narrativa. RECIMA21 - Revista Científica Multidisciplinar - ISSN 2675-6218,2(2), 308-316. https://doi.org/10.47820/recima21.v2i2.100

Bardin, L. Análise de conteúdo. São Paulo: Edições 70, 229 p., 2011.

Bezerra, G. D., Sena, A. S. R., Braga, S. T., dos Santos, M. E. N., Correia, L. F. R., de Freitas Clementino, K. M., ... \& Pinheiro, W. R. (2020). O impacto da pandemia por COVID-19 na saúde mental dos profissionais de saúde: revisão integrativa. Revista Enfermagem Atual In Derme, 93.

Cruz, F. O. A. M.; Ferreira, E. B.; Vasques, C. I. et al.Validation of an educative manual for patients with headand neck cancer submitted to radiation therapy.Rev Latino-Am Enferm, v. 24, p. e2706, 2016. https://doi.org/10.1590/1518-8345.0949.2706

Dantas, Eder Samuel Oliveira. (2021). Saúde mental dos profissionais de saúde no Brasil no contexto da pandemia por Covid-19. Interface - Comunicação, Saúde, Educação [online], v. 25. https://doi.org/10.1590/Interface.200203

Fiho, J. M. J., Assunção, A. Á., Algranti, E., Garcia, E. G., Saito, C. A., \& Maeno, M. (2020). A saúde do trabalhador e o enfrentamento da COVID-19. Revista Brasileira de Saúde Ocupacional, 45. https://doi.org/10.1590/2317-6369ed0000120

Freire, P. (1987). Pedagogia do oprimido. http://www.dhnet.org.br/direitos/militantes/paulofreire/paulo_freire_pedagogia_do_oprimido.pdf

Gallasch, C., Cunha, M., Pereira, L., \& Silva-Junior, J. (2020). Prevenção relacionada à exposição ocupacional do profissional de saúde no cenário de COVID19 [Prevention related to the occupational exposure of health professionals workers in the COVID-19 scenario] [Prevención relacionada cone la exposición ocupacional de profesionales de la salud en el escenario COVID-19]. Revista Enfermagem UERJ, 28, e49596. doi:https://doi.org/10.12957/reuerj.2020.49596

Gerolin, F., Pires, A., Nascimento, C., Schimitt, C., Torquato Salles Bucione, F., Amaral da Rocha6, J., Berlofi, L., \& da Silva Ferrari, L. (2020). Ações de lideranças da Enfermagem na organização do atendimento hospitalar a pacientes com COVID-19. Enfermagem em Foco, 11(2.ESP). doi:https://doi.org/10.21675/2357-707X.2020.v11.n2.ESP.3665

Góes, F. G. B., Silva, A. C. S. S. D., Santos, A. S. T. D., Pereira-Ávila, F. M. V., Silva, L. J. D., Silva, L. F. D., \& Goulart, M. D. C. (2020). Desafios de profissionais de Enfermagem Pediátrica frente à pandemia da COVID-19. Revista Latino-Americana de Enfermagem, 28. https://doi.org/10.1590/15188345.4550 .3367

Haraki C. A. C. Estratégias adotadas na América do Sul para a gestão da infodemia da COVID-19. (2021) Rev Panam Salud Publica45:e43. https://doi.org/10.26633/RPSP.2021.43

Krauzer, I. M; Dall'agnoll, C. M.; Gelbcke, F. L. et al. A construção de protocolos assistenciais no trabalho em Enfermagem. REME -Rev Min Enferm, v. 22, p. e-1087, 2018. https://doi.org/10.5935/1415-2762.20180017

Milani, M. L., \& Vandresen, F. (2019). O programa nacional de segurança do paciente e as implicações nos serviços de saúde como aspecto relevante ao desenvolvimento regional. DRd-Desenvolvimento Regional em debate, 9, 478-505.

Minayo, M. C. d. S. (2014). O desafio do conhecimento (14a ed.). HUCITEC.

Oliveira, E., Costa, M., Marques, N., Lomeo, R., Nascimento, P., Rodrigues, C., Andrade, C., \& Moreira, R. (2020). Projeto Vida em Quarentena: estratégia para promoção da saúde mental de enfermeiros diante da COVID-19. Enfermagem em Foco, 11(1.ESP). doi:https://doi.org/10.21675/2357707X.2020.v11.n1.ESP.3741

Oliveira, T. M. (2020). Como enfrentar a desinformação científica? Desafios sociais, políticos e jurídicos intensificados no contexto da pandemia. Liinc em Revista, 16(2), e5374-e5374. https://doi.org/10.18617/liinc.v16i2.5374

Oliveira, J., Macedo, M., Morais, R., Tanan, M., \& Yarid, S. (2017). Biossegurança sob a ótica dos graduandos de enfermagem [Biosafety in the view of finalyear nursing students] [Bioseguridad bajo la óptica de los estudiantes de enfermería]. Revista Enfermagem UERJ, 25, e14074. doi:https://doi.org/10.12957/reuerj.2017.14074

Organização Panamericana de Saúde. Folha informativa - COVID-19 (doença causada pelo novo coronavírus). Organização Panamericana de Saúde (OPAS). Representação da OPAS no Brasil. 12 de abril de 2020. https://www.paho.org/pt/covid19

Paula GS, Gomes AMT, França LCM, Neto FRA, Barbosa DJ. A enfermagem frente ao processo de morte e morrer: uma reflexão em tempos de Coronavírus. J. nurs. health. 2020;10(n.esp.):e20104018. https://doi.org/10.15210/jonah.v10i4.18977

Quadros, A., Carollo Fernandes, M., Araujo, B., \& Aquino Caregnato, R. (2020). Desafios da Enfermagem Brasileira no Combate da COVID-19: uma reflexão. Enfermagem em Foco, 11(1.ESP). doi:https://doi.org/10.21675/2357-707X.2020.v11.n1.ESP.3748

Ran, L., Chen, X., Wang, Y., Wu, W., Zhang, L., \& Tan, X. (2020). Risk Factors of Healthcare Workers With Coronavirus Disease 2019: A Retrospective Cohort Study in a Designated Hospital of Wuhan in China. Clinical infectious diseases : an official publication of the Infectious Diseases Society of America, 71(16), 2218-2221. https://doi.org/10.1093/cid/ciaa287 
Research, Society and Development, v. 10, n. 10, e350101018724, 2021

(CC BY 4.0) | ISSN 2525-3409 | DOI: http://dx.doi.org/10.33448/rsd-v10i10.18724

Ribeiro, B. C. O., de Souza, R. G., \& da Silva, R. M. (2019). A importância da educação continuada e educação permanente em unidade de terapia intensivarevisão de literatura. Revista de Iniciação Científica e Extensão, 2(3), 167-175.

Rodrigues N. H., Silva L. G. A. (2020) Gestão da pandemia Coronavírus em um hospital: relato de experiência profissional. J. nurs. health., 10(n.esp.):e20104004 https://doi.org/10.15210/jonah.v10i4.18530

Sena Lima, R. M. L., de Moura, M. V., da Cruz Matos, J., Walter, K. C., Araújo, V. S., Cavalcante, E. S., ... \& Sisnando, M. S. M. (2021). Conhecimento dos enfermeiros acerca da importância do uso de protocolos de cuidados: Discurso do sujeito coletivo. Research, Society and Development, 10(1), e15810111186e15810111186. http://dx.doi.org/10.33448/rsd-v10i1.11186

Teixeira, C. F. D. S., Soares, C. M., Souza, E. A., Lisboa, E. S., Pinto, I. C. D. M., Andrade, L. R. D., \& Espiridião, M. A. (2020). A saúde dos profissionais de saúde no enfrentamento da pandemia de Covid-19. Ciência \& Saúde Coletiva, 25, 3465-3474. Doi:https://doi.org/10.1590/1413-81232020259.19562020 